\title{
Article \\ Role of Solvent Polarity on Dispersion Quality and Stability of Functionalized Carbon Nanotubes
}

\author{
Dhivakar Rajendran (1), Rajarajan Ramalingame, Anurag Adiraju, Hanen Nouri and Olfa Kanoun *(1) \\ Measurement and Sensor Technology, Chemnitz University of Technology, Reichenhainer Straße 70, \\ 09126 Chemnitz, Germany; dhivakar.rajendran@etit.tu-chemnitz.de (D.R.); \\ rajarajan.ramalingame@etit.tu-chemitz.de (R.R.); Adiraju.Anurag@etit.tu-chemnitz.de (A.A.); \\ hanen.nouri@etit.tu-chemnitz.de (H.N.) \\ * Correspondence: olfa.kanoun@etit.tu-chemnitz.de
}

\begin{abstract}
Dispersion of carbon nanotubes (CNT) in solvents and/or polymers is essential to reach the full potential of the CNTs in nanocomposite materials. Dispersion of CNTs is especially challenging due to the van-der-Waals attraction forces between the CNTs, which let them tend to re-bundle and/or re-aggregate. This paper presents a brief analysis of the quality and stability of functionalized multiwalled carbon nanotubes (fMWCNT) dispersion on polar solvents. A comparative study of functionalized CNT dispersion in water, methyl, and alcohol-based organic solvents has been carried out and the dispersion has been characterized by UV-VIS spectroscopy, electrochemical characterization such as cyclic voltammetry (CV) and electrochemical impedance spectroscopy (EIS). Visual analysis of the dispersion has been investigated for up to 14 days to assess the dispersion's stability. Based on the material characterization, it was observed that the degree of affinity fMWCNT with - $\mathrm{COOH}$ group highly depends on the polarity of the solvent, where the higher the polarity, the better the interaction of fMWCNT with solvents.
\end{abstract}

Keywords: carbon nanotubes; polar solvents; UV-VIS analysis; electrochemical impedance spectroscopy (EIS)

Ramalingame, R.; Adiraju, A.; Nouri, H.; Kanoun, O. Role of Solvent Polarity on Dispersion Quality and Stability of Functionalized Carbon Nanotubes. J. Compos. Sci. 2022, 6, 26. https://doi.org/10.3390/jcs6010026

Academic Editor:

Francesco Tornabene

Received: 25 December 2021

Accepted: 7 January 2022

Published: 11 January 2022

Publisher's Note: MDPI stays neutral with regard to jurisdictional claims in published maps and institutional affiliations.

Copyright: (๑) 2022 by the authors. Licensee MDPI, Basel, Switzerland. This article is an open access article distributed under the terms and conditions of the Creative Commons Attribution (CC BY) license (https:// creativecommons.org/licenses/by/ $4.0 /)$.

\section{Introduction}

Carbon nanotubes (CNTs) are among the most promising nanofillers in the field of nanocomposite sensors due to their high aspect ratio, excellent mechanical properties, good electrical and thermal conductivity, which are essential properties for many applications [1]. It was reported that CNTs can enhance the photo-catalysis perfomance of $\mathrm{ZnO}$ and $\mathrm{TiO}_{2}$ due to its unique electronic and adsorption properties [2-4]. Furthermore, CNTs have advantageous adsorption, catalytic, and electrochemical characteristics, which make it possible to combine adsorption, catalysis, or electrochemistry with the membrane separation process, hence increasing the water treatment efficiency of CNTs-based composite membranes [5]. The proper transfer of these properties can be achieved by the effective dispersion of CNTs within solvents and/or polymers. Many works have been investigating how to achieve the effective dispersion of CNT in solvents and polymers. However, it remains a very challenging task given the entanglement as well as breakage of CNTs that occurs during processing in addition to the poor interfacial interaction between the CNTs and the dispersing medium [6]. Several approaches applying physical shear stress have been adopted to break down CNT bundles and disperse it dispersing medium [7,8], such as shear mixing, mechanical stirring, and sonication. It has been reported that the addition of functional groups, macro-molecules and bio-molecules onto the CNT walls in various applications from nanoelectronics to bio-applications $[9,10]$. Indeed, adding functional groups such as - $\mathrm{COOH},-\mathrm{OH}$ and $-\mathrm{NH}_{2}$ using covalent and/or non-covalent functionalization modifies the surface of CNT prevents nanotube aggregation, which helps to better disperse and stabilize the CNT within a solvent $[8,11-13]$. The functionalization of 
CNTs has been reported as a possibility for reducing the agglomerates formations and for enhancing the hydrophilic nature of the CNTs [14]. When the surface of a CNT suffers from oxidation, chemical elements are adsorbed, forming functional groups. These functional groups interact with solvents via polar-polar interaction, which results in the formation of hydrogen bonds, so that the CNTs to repel each other, preventing the formation of agglomerates [15]. Figure 1 shows the hydrogen bond between the functional group on CNT and water, enabling CNT in a dispersed state in water.
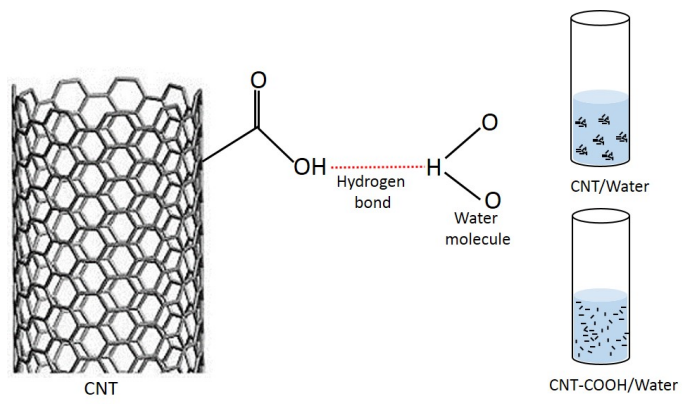

Figure 1. Hydrogen bonding between the $\mathrm{CNT}-\mathrm{COOH}$ and water.

Functionalized CNTs can achieve a stable dispersion compared to non-functionalized CNTs through visual tests over a certain time [16]. It is also reported that the modified nanotubes are highly soluble in polar solvents such as water, ethanol and dimethylformamide, depending on degree of functionalization and nature of the functional groups attached on it $[17,18]$. An analysis of the dispersion stability of surface-modified CNTs on polar and non-polar solvents using a qualitative measurement technique based on multiple light scattering [19]. When the CNTs were modified with carboxylic anions, the dispersibility in polar solvents was enhanced due to the combination of polar-polar affinity and electrostatic repulsion between the functional groups and polar solvents [19]. A polysilicone flame retardant (PA) was synthesized and grafted onto the surface of carbon nanotubes (CNTs) via amide linkages to obtain modified CNTs (CNTs-PA) and it is stable and soluble in water and high polar solvents [20]. A study presented a controlled dispersion of carbon nanotubes in polyethylene through surface modification using a mixture of concentrated acid and octadecylamine (ODA) where dispersion stability is strongly depends on solvent and carbon nanotube polarities after the functionalization using visual investigation [21]. An investigation of the interfacial properties of multiwalled CNTs (MWCNTs) exposed to widely utilized solvents by sum frequency generation vibrational spectroscopy (SFG-VS) to probe solvent-wetted MWCNTs. It proved that polar solvents can substantially alter the interfacial optical property of MWCNTs [22]. It was investigated that the affinity of acid-treated CNTs with water highly depends on the contents of $\mathrm{COOH}$ groups attached on the outer walls of CNT and solubility of CNT in water is quantified by measuring the PH value of the dispersion [23]. A large-scale all-atom molecular dynamics simulation has been adopted to study the dispersibility behavior of the functionalized CNT in various polar solvents, and it has been stated, that the dispersion behavior should be dependent on the polarity of the solvents [24]. Although significant efforts have been devoted to investigating dispersion improvements by functionalized CNT in polar and non-polar solvents, a quantitative analysis of the influence of CNT's functionalization on their affinity to the polarity of the solvent has never been carried out. The solvent polarity index is related to polar interaction and hydrogen bonding parameters based on the Hansen solubility parameters. It can be seen that the higher the polarity index, the stronger the polar interaction and hydrogen bonding between the molecules [25]. This leads to a hydrogen bonding between the functional groups in the CNTs and solvent, resulting in faster and stable separation of CNTs in the solvents. Table 1 shows that Hansen solubility parameter and polarity index of various solvents, where $\delta_{p}$ is energy from dipole force between molecules and $\delta_{h}$ is the energy from hydrogen bonds between molecules. 
Table 1. Hansen solubility parameter for polar solvents.

\begin{tabular}{cccc}
\hline Solvent & Polarity Index & $\delta_{h}$ & $\delta_{\boldsymbol{p}}$ \\
\hline Water & 10.2 & 20.7 & 7.8 \\
Ethanol & 5.2 & 9.5 & 4.3 \\
2-propanol & 4.0 & 8.5 & 3.3 \\
Toluene & 2.0 & 3.5 & 2.6 \\
\hline
\end{tabular}

For analyzing the influence of polar solvents on the CNT dispersion, several aspects need to be investigated to assess the degree of CNTs unbundling and its influence on the resulting properties of nanocomposites. Interesting are thereby optical, electrical and chemical methods. In this work, the affinity of functionalized multiwalled carbon nanotubes (fMWCNT) to polar solvents by investigating the dispersion quality and stability by UV-VIS analysis and electrochemical methods such as cyclic voltammetry and electrochemical impedance spectroscopy (EIS).In UV-VIS measurements, individual fMWCNT show a characteristic absorption band in the UV region [26]. Based on this, the degree of CNT unbundling can be assessed in a liquid medium. The homogeneous dispersion of carbon nanotubes (CNTs)in solvents affects the electrical conductivity of the thin films based on $\mathrm{CNT} /$ solvent dispersion. Among various approaches, the electrochemical characterization technique can be very useful in studying and characterizing the degree of the CNT dispersion in a quantitative way. In cyclic voltammetry, exfoliated CNTs can increase the electroactive surface area compared to the agglomerated state, resulting in more charge transfer. The tunneling resistance is calculated using EIS to evaluate the degree of exfoliated fMWCNT. Indeed, a visual investigation of the dispersion has been carried out over 14 days to evaluate the stability of the dispersion.

\section{Materials and Methods}

In this work, MWCNT functionalized with - $\mathrm{COOH}$ group (fMWCNT) was purchased from NanoAmor Inc, USA and the diameter and length of MWCNTs are 8-15 nm and $0.5-2 \mu \mathrm{m}$, respectively. Some of the previous works recommended some organic solvents for achieving the effective dispersion of CNT $[8,27]$. Thus, organic solvents, namely 2-propanol, ethanol, water, and toluene, were selected. Three samples were prepared by mixing $0.05 \mathrm{wt} . \%$ of CNT in $20 \mathrm{~mL}$ of solvent and sonication at $30 \%$ amplitude at $0.5 \mathrm{~s}$ using MS73 sonotrode in Bandlein Sonoplus ultrasonicator for different durations (10 min, $30 \mathrm{~min}$, $60 \mathrm{~min}, 90 \mathrm{~min}$, and $120 \mathrm{~min}$ ) to determine the optimum sonication time for an effective unbundling of the CNTs. Figure 2 shows the preparation of CNT/solvent dispersion.

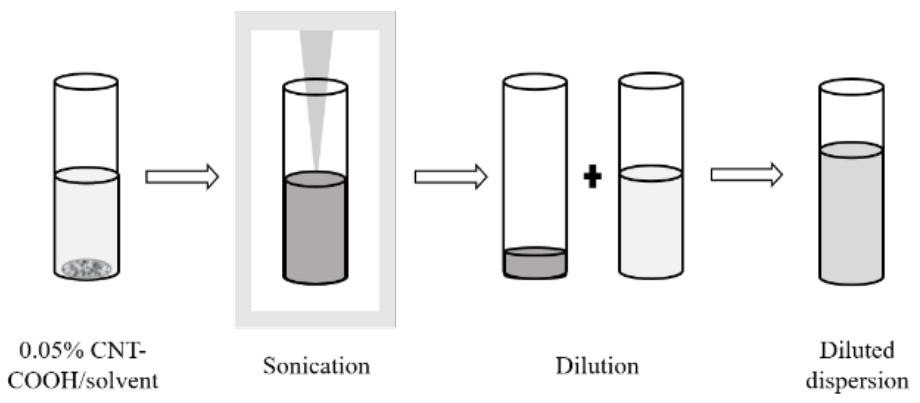

Figure 2. fMWCNT dispersion process.

In order to perform the UV-VIS analysis, the dispersion must be diluted in the ratio 1:100 for the sufficient transmittance within UV-VIS spectroscopy and hence, $60 \mu \mathrm{L}$ of $\mathrm{CNT}$ / solvent dispersion is diluted in $600 \mu \mathrm{L}$ of their respective solvents and analyzed using UV-VIS spectrometer (Perkin Elmer Lambda 700) operating in the range of $260-700 \mathrm{~nm}$. Initially, baseline correction was carried out using $5 \mathrm{~mL}$ of solvent. The results show that, 
as sonication time increases, the probability of the CNT unbundling gets higher, which indicates a higher number of individual CNTs dispersed in the solvents [28].

Hence the absorption curve of the UV-VIS spectrum also increases (see Figure 3a). Figure $3 b$ shows the diluted dispersion of fMWCNT/2-propanol subjected to UV-VIS analysis. Dispersion stability was characterized by performing the UV-VIS analysis at the day of dispersion preparation, 7th day and 14th day after the dispersion prepared and the variation of absorbance is analyzed. Higher the variance of absorbance, the lesser the stability of the dispersion. For electrochemical characterization, the ItalSens screen printed electrodes were purchased from Palmsens, where the working and counter electrode was made of carbon and the reference electrode was silver. The electrode is modified by casting a $0.5 \mu \mathrm{L}$ of $\mathrm{fMWCNT} /$ solvent dispersion at different sonication times and dried for $5 \mathrm{~min}$ at room temperature. The electrochemical measurement was performed in $0.1 \mathrm{M} \mathrm{Kcl}$ containing $5 \mathrm{mM} \mathrm{Fe}(\mathrm{CN})_{6}^{3-/ 4-}$ to characterize the modified electrode performance.

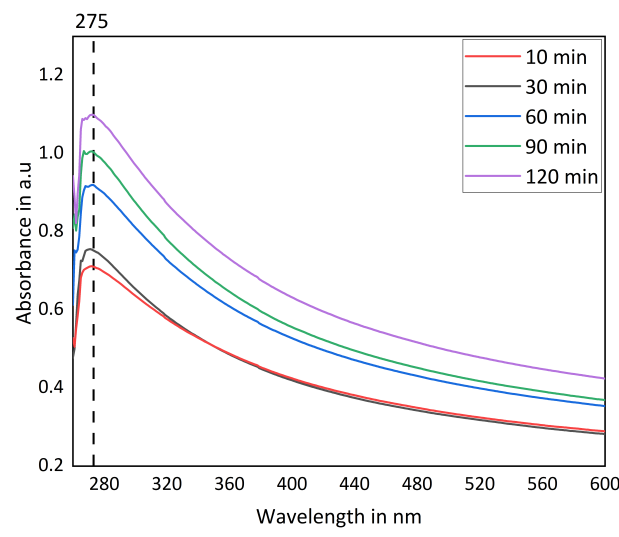

(a)

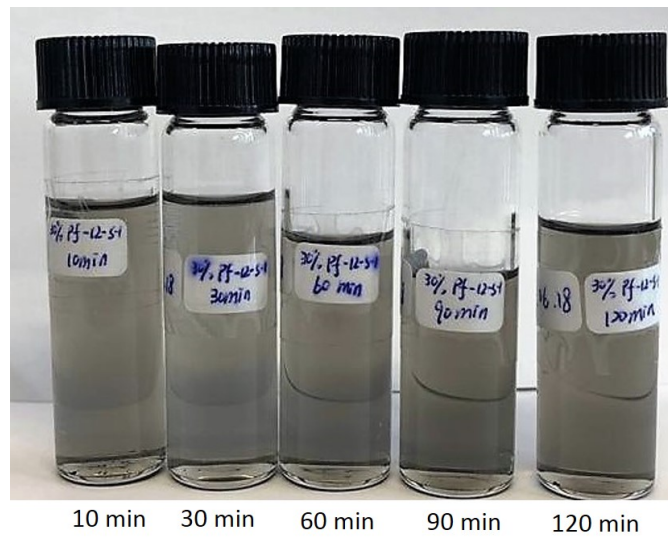

(b)

Figure 3. (a) UV-VIS spectrum of different fMWCNT dispersions with different duration of ultrasonic treatments; (b) Diluted fMWCNT/2-propanol dispersions at different sonication time.

\section{Results}

\subsection{UV-VIS Analysis}

Figure 4 shows the absorbance value of fMWCNT dispersion in various solvents.

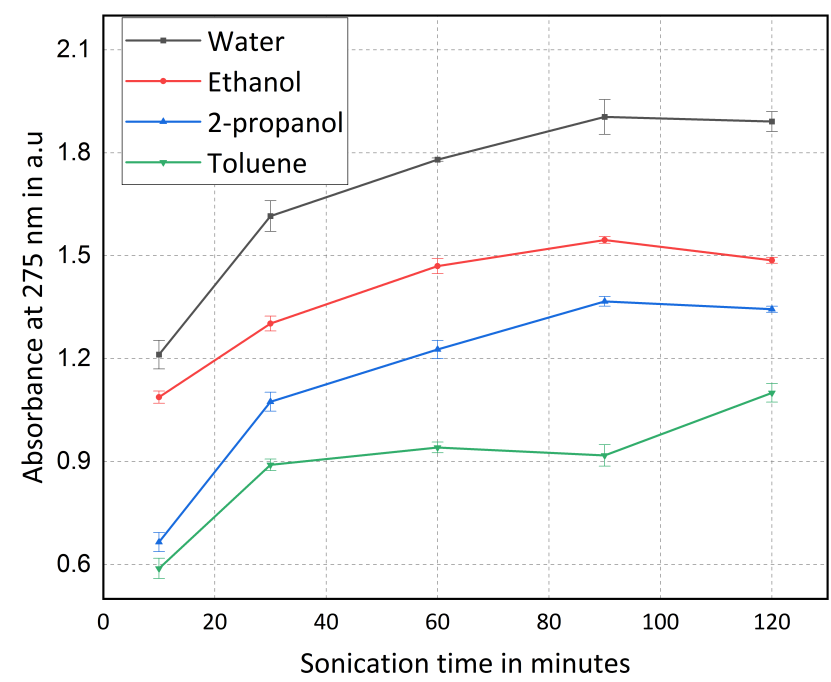

Figure 4. Rate of debundled CNT in solvents for different sonication time.

In all dispersion, an increase in sonication time enhances the dispersion of fMWCNT in solvents, which can be observed in Figure 4. An increase in sonication time unbundles more 
CNTs, which increases absorption [29]. Absorbance is saturated after a particular sonication time and decreases with increased sonication time. A long time of ultrasonication provides more energy, which can be prone to fracture or damage CNT resulting in a reduction of its characteristic peak [29]. It can also be seen that the absorbance values in all sonication time are higher in polar solvents such as water compared to a low polar solvent such as toluene. Figure 5 shows the deviation in the absorption spectrum at $275 \mathrm{~nm}$ measured at the day of sonication, 7 days, and 14 days after the dispersion was sonicated. The smaller the deviation, the more dispersion stability can be assumed. For fMWCNT dispersion in water, ethanol 2-propanol and toluene, the absorbance varied from $0.5 \%$ to $0.963 \%$, $0.871 \%$ to $2.19 \%$ and $2.972 \%$ to $6.124 \%$ and $3.482 \%$ to $21.2 \%$ at different sonication time 10 to $120 \mathrm{~min}$ respectively. It can be seen that the stability of the dispersion is highly dependent on the solvent, which follows the order: Water $>$ ethanol $>2$-propanol $>$ toluene. The stronger hydrogen bonding between the functional groups on the fMWCNT wall and solvent enables the fMWCNT in the exfoliated state.

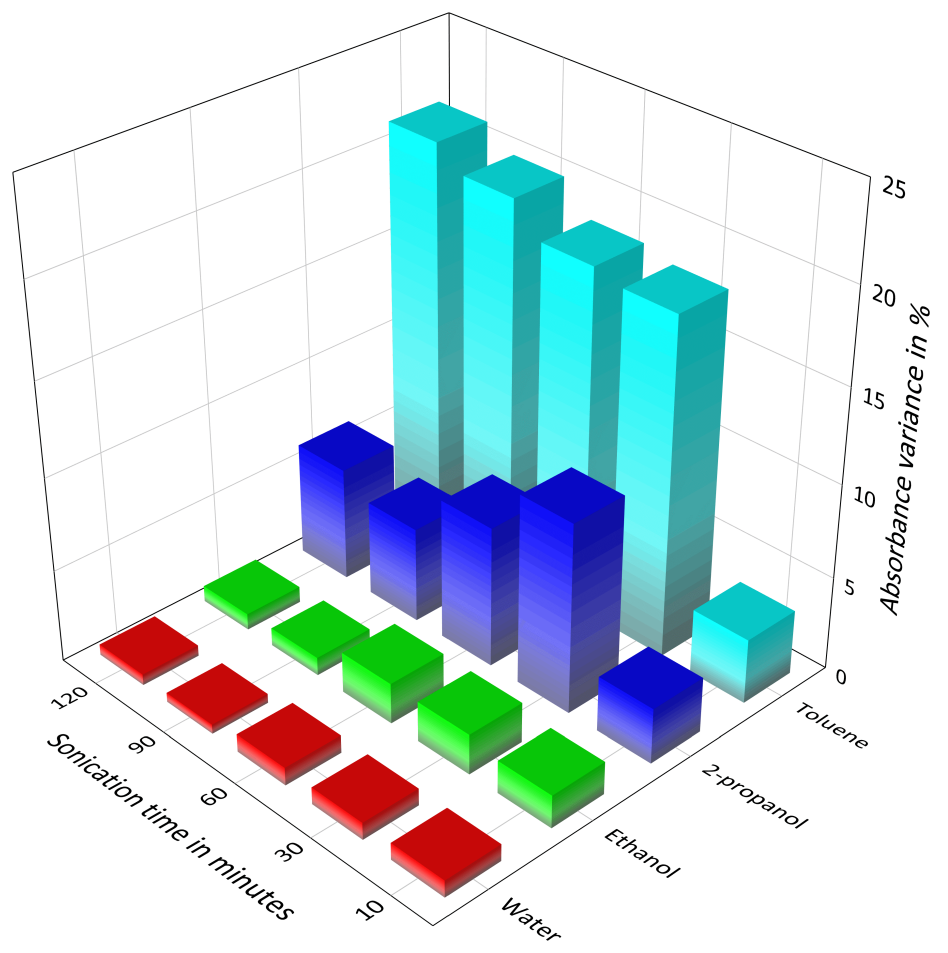

Figure 5. Dispersion stability of fMWCNT in different solvents.

\subsection{Visual Analysis}

Visual analysis was performed after 1 day, 7 days, and 14 days from the dispersion prepared. Figures 6-8 shows digital pictures of fMWCNT dispersion in polar organic solvents for 1 day, 7 days, and 14 days after ultrasonication. It can be inferred that the fMWCNT is dispersed in the toluene starts to sediment after a day of ultrasonication. After 7 days, there is slight sedimentation in the fMWCNT /2-propanol dispersion and fMWCNT was settled down in toluene, indicating the poor dispersion. After 14 days, there is evident precipitation of fMWCNT in toluene and 2-propanol shows poor dispersion stability in low polar solvents. 


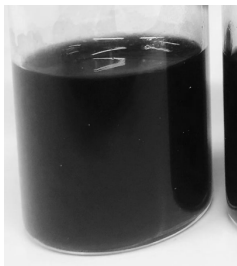

(a)

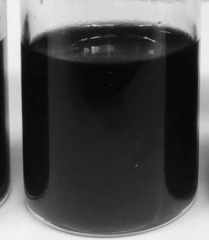

(b)

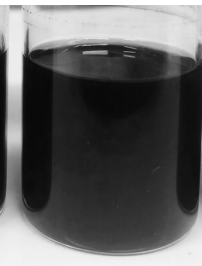

(c)

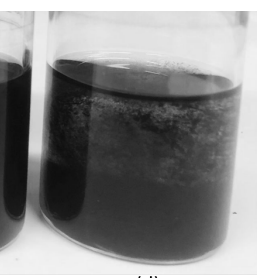

Figure 6. fMWCNT/solvent dispersion after 1 day: (a) Water; (b) Ethanol; (c) 2-propanol; (d) Toluene.

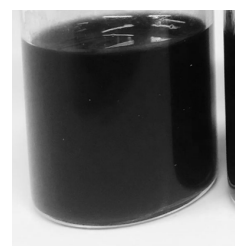

(a)

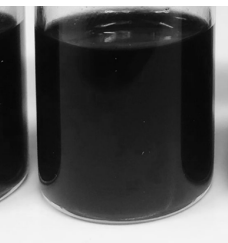

(b)

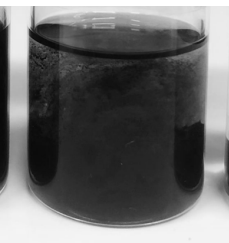

(c)

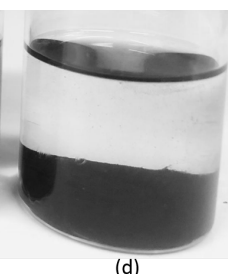

Figure 7. fMWCNT/solvent dispersion after 7 days: (a) Water; (b) Ethanol; (c) 2-propanol; (d) Toluene.

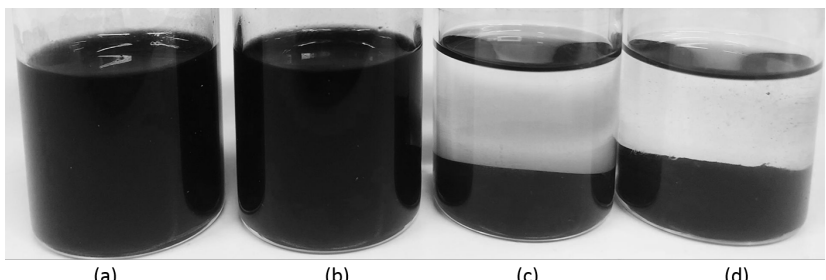

(c)

(d)

Figure 8. fMWCNT/solvent dispersion after 14 days: (a) Water; (b) Ethanol; (c) 2-propanol; (d) Toluene.

On the other hand, dark dispersion of fMWCNT is water and ethanol show no visible precipitation of fMWCNT and was stable after 14 days. The stability of dispersion based on visual analysis is correlating to the change in absorbance value which is shown in Figure 5.

\subsection{Electrochemical Characterization}

Figure 9 shows the cyclic voltammetry $(\mathrm{CV})$ response of the modified electrodes based on fMWCNT dispersion in various polar solvents using $5 \mathrm{mM} \mathrm{Fe}(\mathrm{CN})_{6}^{3-/ 4-}$ in $0.1 \mathrm{M} \mathrm{KNO}_{3}$. It can be inferred that the potentials of the redox couple is between 0.3 to $0.34 \mathrm{~V}$. The electrochemical response is significantly enhanced at modified electrode based fMWCNT dispersion which reflects the improvement of both the shape of redox peak and magnitude of the peak current $\left(i_{p}\right)$. According to the Randles-Ševcík equation,

$$
i_{p}=2.69 \times 10^{5} \cdot A \cdot C \cdot \sqrt{D} \sqrt{v} n^{3 / 2}
$$

where $i_{p}$ is the peak current $(A), A$ is the electroactive surface area $\left(\mathrm{cm}^{2}\right), C$ is the concentration of the electroactive redox species in the solution $\left.(\mathrm{mol} \mathrm{cm})^{3}\right), \mathrm{D}$ is the diffusion coefficient of the analyte $\left(\mathrm{cm}^{2} \mathrm{~s}^{-1}\right), \mathrm{v}$ is the applied scan rate $\left(\mathrm{V} \mathrm{s}^{-1}\right)$ and $\mathrm{n}$ is the number of electrons involved in the redox process [30]. The peak current is directly related to the electroactive surface area.

From Figure 9, it can be seen that in all fMWCNT dispersion, the peak current in $\mathrm{CV}$ response increases with an increase in sonication time. This is because, during the unbundling process, more individual fMWCNT cover a large area on the surface of the electrodes compared to the agglomerated state. This increases the electroactive surface area and more significant electron transfer, which leads to an increase in peak current. Figure 10 shows the peak current values of the modified electrode based on fMWCNT dispersion in different solvents. 


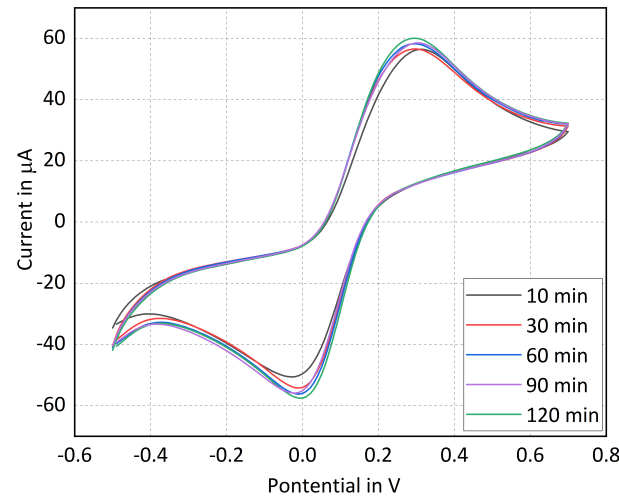

(a)

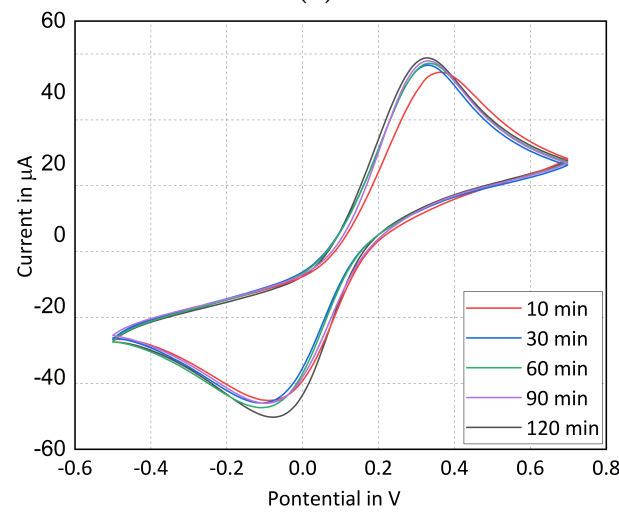

(c)

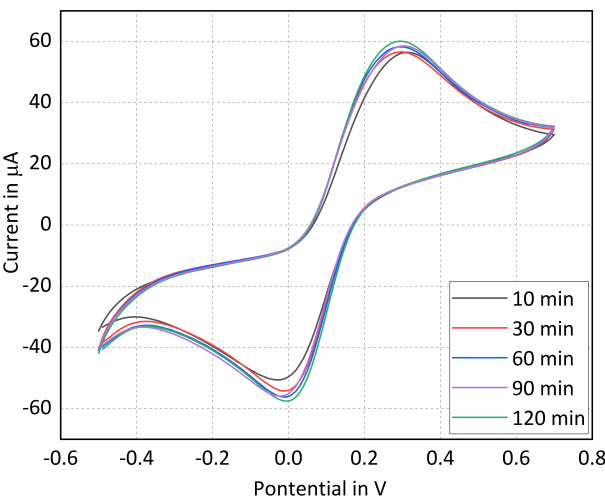

(b)

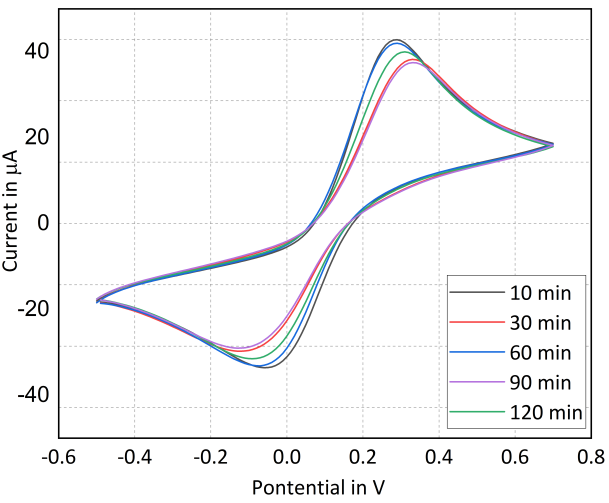

(d)

Figure 9. Cyclic voltammetric of fMWCNT dispersion in solvents at different sonication time. (a) Water; (b) Ethanol; (c) 2-propanol; (d) Toluene.

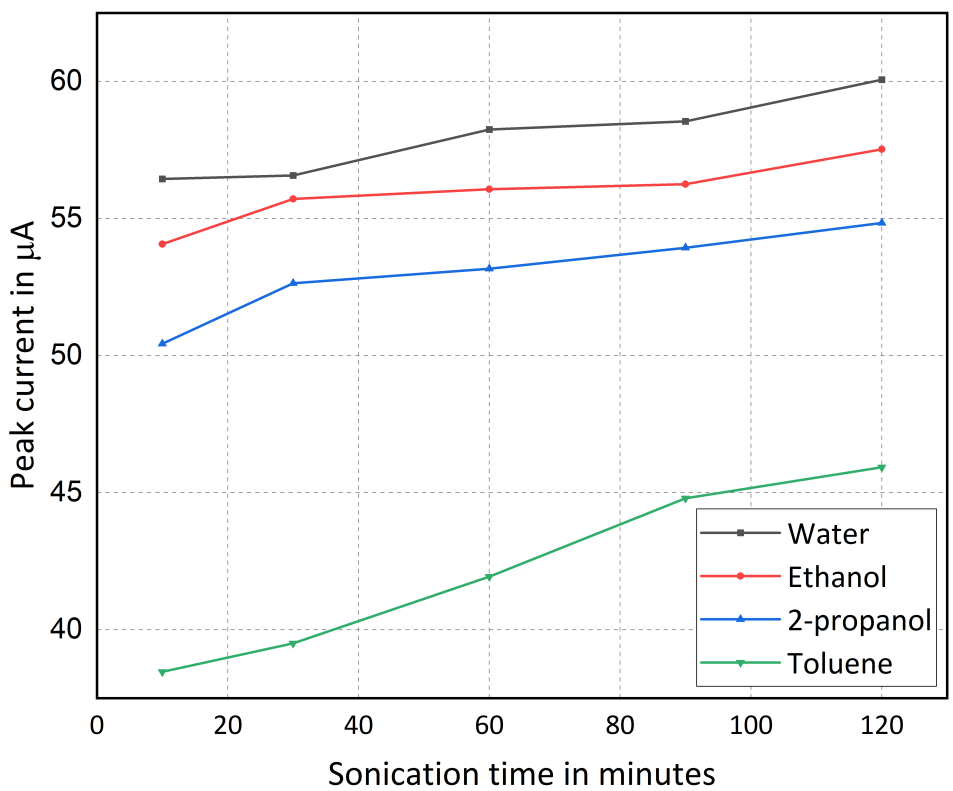

Figure 10. Comparison among the current peak values of electrode based on $\mathrm{fMWCNT}$ dispersion in different solvents.

It can be seen that the ratio of the peak current of modified electrode based on CNT dispersion in high polar solvents such as water to that of dispersion in ethanol, 2-propanol, and toluene was calculated to be 1.04,1.12, and 1.43, respectively. At all sonication time, the peak current values of the modified electrodes based fMWCNT dispersion in a solvent which follows the order: Water $>$ ethanol $>2$-propanol $>$ toluene. Indeed this 
characterization technique compares the affinity of fMWCNT with solvents and the exact number of surface groups cannot be determined due to an incomplete definition of surface redox reactions.

In the dispersion, fMWCNT is randomly distributed in the solvent, which form R-C complex network. By using EIS, an investigation of the complex conduction mechanism in the fMWCNT network can be carried out to evaluate the quality of fMWCNT dispersion with different solvents.

Figure 11 shows the impedance response of the modified electrode based on CNT dispersion in toluene, which exhibits a quasi-semicircle response. In order to evaluate the electrical transport mechanisms in the fMWCNT network, an equivalent circuit was fitted to the impedance response. The equivalent circuit consists of a resistor $R_{C N T}$ is series with a parallel combination of $R_{t}$ and a constant phase element. Each nanotube or nanotube agglomerates has an intrinsic resistance referred to as $R_{C N T}$ and $R_{t}$ represents the tunneling resistance between the CNT when it is randomly distributed in the solvents. According to Simon's theory, the tunneling resistance can be expressed as [31],

$$
R_{T}=\frac{h^{2} d}{A e^{2 \sqrt{2 m \lambda}}} \times e^{\frac{4 \pi d}{h} \sqrt{2 m \lambda}}
$$

where $d$ is the distance between MWCNT, $h$ is the Planck constant, $e$ is the quantum of electricity, $l$ is the barrier height of energy, $m$ is the electron mass, and $A$ is the cross-sectional area of the tunnel [31,32]. Based on this equation, the tunneling resistance decreases if the distance between the CNT decreases. Figure 12 shows the influence of $\mathrm{R}_{t}$ of CNT dispersion in both agglomerated and dispersed state.

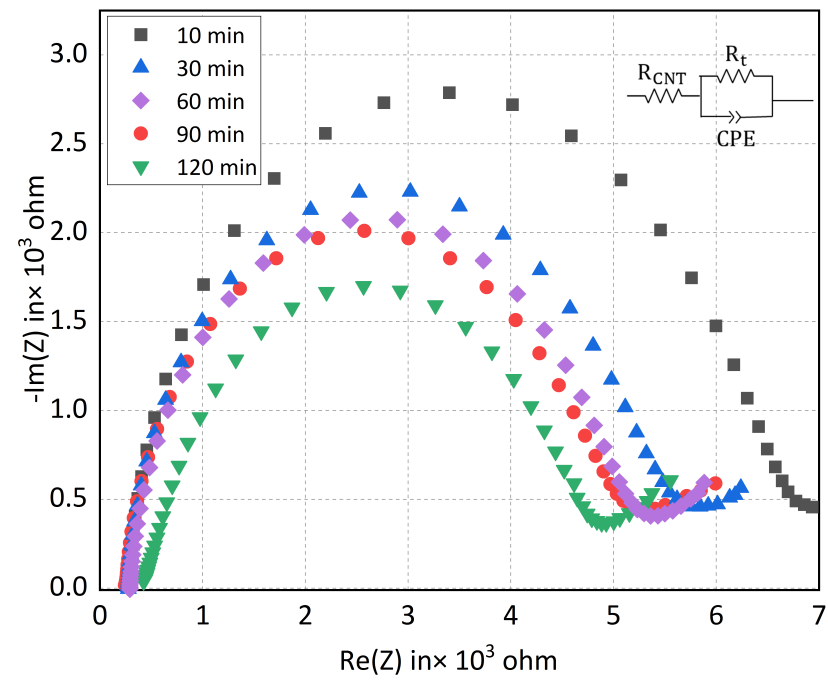

Figure 11. Nyquist plot of modified electrode based on fMWCNT/Toluene dispersion.

Initially, fMWCNT are formed as clusters due to Van-der-Waals forces and the distance between the clusters is high. During the sonication, fMWCNT clusters break down as individual fMWCNT where the distance between the fMWCNT reduces leading to a reduced tunneling resistance $\left(R_{t}\right)$. This can be seen in the Figure 11, increasing the sonication time a comprehensive decrease in the radius of the quasi-semicircle, which means that there is a decrease in tunneling resistance $\left(\mathrm{R}_{t}\right)$ due to the distance between the fMWCNT reduces during their unbundling process. 


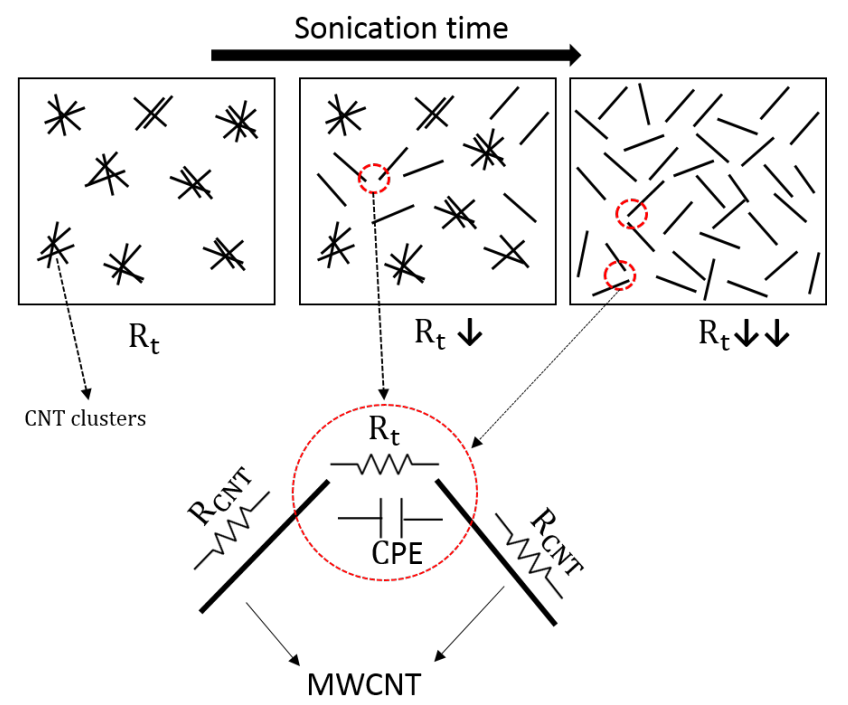

Figure 12. Influence of tunneling resistance due to sonication of fMWCNT dispersion

The impedance response has been fitted to an equivalent circuit model and the corresponding circuit parameters were extracted to determine the tunneling resistance. Figure 13 shows the tunnelling resistance of fMWCNT in various solvents. It can be seen that the tunnelling resistance decreases with the increases in all sonication time for fMWCNT in all solvents. The highest value is $6.323 \mathrm{k} \Omega$ for $\mathrm{fMWCNT} /$ Toluene dispersion at $15 \mathrm{~min}$ of sonication and the lowest value is $1.083 \mathrm{k} \Omega$ for fMWCNT/Water dispersion at $120 \mathrm{~min}$ of sonication. Compared to the fMWCNT dispersion based on high polar solvent such as water, the tunnelling resistance is reduced from $73.03 \%$ to $73.35 \%$ in fMWCNT dispersion in a low polar solvent such as toluene. This means more fMWCNT is dispersed, and the distance between them is reduced. At all sonication time, the tunnelling resistance $\left(\mathrm{R}_{t}\right)$ values of the modified electrodes based fMWCNT dispersion in a solvent which follows the order: Water $<$ ethanol $<2$-propanol $<$ toluene.

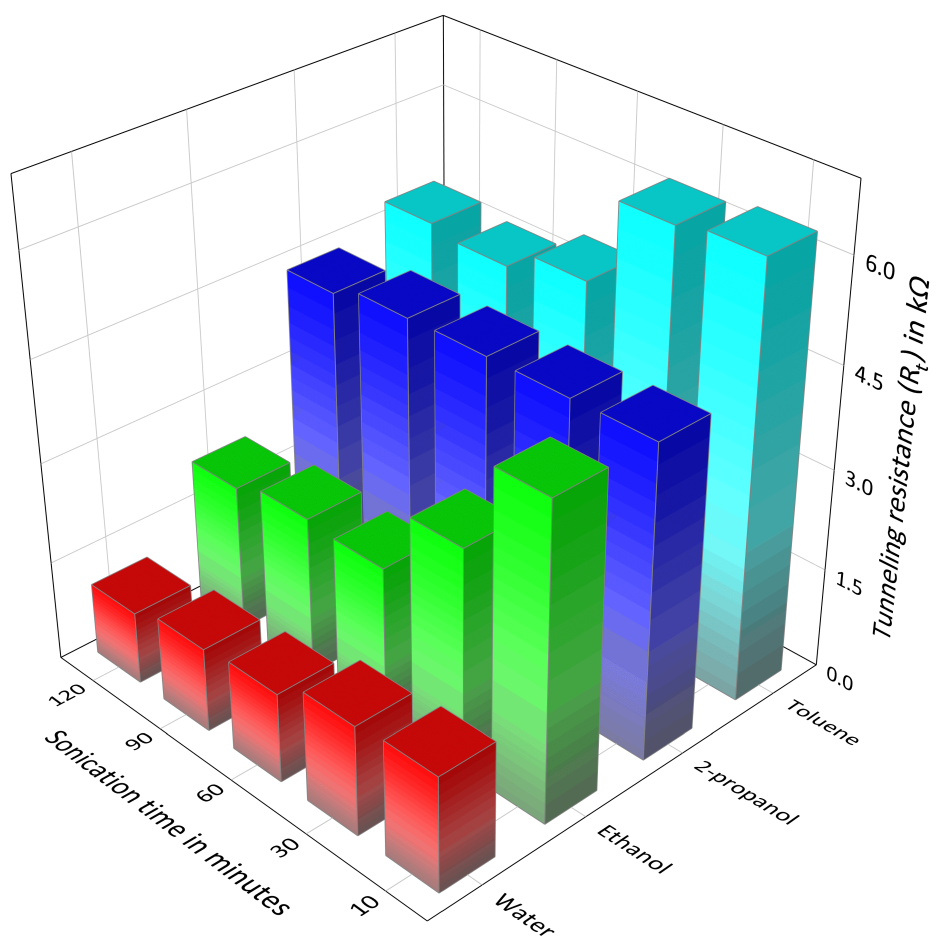

Figure 13. Influence of tunneling resistance due to fMWCNT dispersion in various solvents. 


\section{Conclusions}

The influence of the solvents polarity on the dispersion quality of functionalized carbon nanotubes and stability has been investigated for solvents such as water, ethanol, 2-propanol, and toluene. The quality and stability of dispersion have been characterized by evaluating the absorption of UV-light by individual fMWCNT in the dispersion, where high absorbance is better the dispersion quality, and more minor variation in absorbance over a certain time shows the stability of the dispersion. Further, the dispersion quality is evaluated by cyclic voltammetry and electrochemical impedance spectroscopy using modified electrodes based on fMWCNT dispersion in various solvents. Based on cyclic voltammetry studies, compared to the agglomerated condition, the unbundling procedure results in a more significant number of individual fMWCNT covering a larger area on the surface of the electrodes. This increases the electroactive surface area and increases electron transport, resulting in a rise in peak current. In the EIS study, the tunneling resistance reduces due to the distance between the $\mathrm{CNT}$ decreases during the unbundling process of fMWCNT. Based on conducted studies, the affinity of the fMWCNT is highly dependent on the polarity of solvents that follow the order: Water $>$ ethanol $>2$-propanol $>$ toluene. Indeed, the visual investigation shows that the degree of dispersion depends on the polarity of the solvent. Based on this work, it can be concluded that an efficient and stable fMWCNT dispersion in high polar solvents can be achieved at a lesser sonication time compared to low polar solvents.

Author Contributions: Conceptualization, methodology, and writing-original draft preparation, D.R.; writing-review and editing, supervision, R.R., O.K.; electrochemical measurement, A.A.; Electrochemical impedance analysis, H.N. All authors have read and agreed to the published version of the manuscript.

Funding: The research work is carried out under the project "SmarthouB/M-ERA.net (100581056)" funded by Sächsische Aufbaubank (SAB).

Institutional Review Board Statement: Not applicable.

Informed Consent Statement: Not applicable.

Data Availability Statement: The data that support the findings of this study are available from the corresponding author, upon reasonable request.

Conflicts of Interest: The authors declare no conflict of interest.

\section{Abbreviations}

The following abbreviations are used in this manuscript:

$\begin{array}{ll}\text { CNT } & \text { Carbon Nano Tubes } \\ \text { fMWCNT } & \text { Functionalized Carbon nanotubes } \\ \text { UV-VIS } & \text { Ultra Violet VISible } \\ \text { CV } & \text { Cyclic Voltammetry } \\ \text { EIS } & \text { Electrochemical Impedance Spectroscopy }\end{array}$

\section{References}

1. Tkalya, E.E.; Ghislandi, M.; de With, G.; Koning, C.E. The use of surfactants for dispersing carbon nanotubes and graphene to make conductive nanocomposites. Curr. Opin. Colloid Interface Sci. 2012, 17, 225-232. [CrossRef]

2. Feng, S.-A.; Zhao, J.-H.; Zhu, Z.-P. The manufacture of carbon nanotubes decorated with zns to enhance the zns photocatalytic activity. New Carbon Mater. 2008, 23, 228-234. [CrossRef]

3. al Mayyahi, A.; Everhart, B.M.; Shrestha, T.B.; Back, T.C.; Amama, P.B. Enhanced charge separation in tio 2/nanocarbon hybrid photocatalysts through coupling with short carbon nanotubes. RSC Adv. 2021, 11, 11702-11713. [CrossRef]

4. Sohail, M.; Xue, H.; Jiao, Q.; Li, H.; Khan, K.; Wang, S.; Feng, C.; Zhao, Y. Synthesis of well-dispersed tio2/cnts@ cofe2o4 nanocomposites and their photocatalytic properties. Mater. Res. Bull. 2018, 101, 83-89. [CrossRef]

5. Lee, J.; Jeong, S.; Liu, Z. Progress and challenges of carbon nanotube membrane in water treatment. Crit. Rev. Environ. Sci. Technol. 2016, 46, 999-1046. [CrossRef] 
6. Gerlach, C.; Kanoun, O. Optimization of ultrasonic parameters for deagglomeration of carbon nanotubes within 1-methy1-2pyrrolidinone (nmp) dispersion. In Proceedings of the 2016 Nanotechnology for Instrumentation and Measurement (NANOfIM), Chemnitz, Germany, 8-9 September 2016; pp. 5-16.

7. Sanli, A.; Ramalingame, R.; Kanoun, O. Piezoresistive pressure sensor based on carbon nanotubes/epoxy composite under cyclic loading. In Proceedings of the 2018 IEEE International Instrumentation and Measurement Technology Conference (I2MTC), Houston, TX, USA, 14-17 May 2018; pp. 1-5.

8. Liu, C.-X.; Choi, J.-W. Improved dispersion of carbon nanotubes in polymers at high concentrations. Nanomaterials 2012, 2, 329-347. [CrossRef]

9. Punetha, V.D.; Rana, S.; Yoo, H.J.; Chaurasia, A.; McLeskey, J.T., Jr.; Ramasamy, M.S.; Sahoo, N.G.; Cho, J.W. Functionalization of carbon nanomaterials for advanced polymer nanocomposites: A comparison study between cnt and graphene. Prog. Polym. Sci. 2017, 67, 1-47. [CrossRef]

10. Balasubramanian, K.; Burghard, M. Chemically functionalized carbon nanotubes. Small 2005, 1, 180-192. [CrossRef] [PubMed]

11. Kim, S.W.; Kim, T.; Kim, Y.S.; Choi, H.S.; Lim, H.J.; Yang, S.J.; Park, C.R. Surface modifications for the effective dispersion of carbon nanotubes in solvents and polymers. Carbon 2012, 50, 3-33. [CrossRef]

12. Ma, P.-C.; Siddiqui, N.A.; Marom, G.; Kim, J.-K. Dispersion and functionalization of carbon nanotubes for polymer-based nanocomposites: A review. Compos. Part A Appl. Sci. Manuf. 2010, 41, 1345-1367. [CrossRef]

13. Yook, J.Y.; Jun, J.; Kwak, S. Amino functionalization of carbon nanotube surfaces with nh3 plasma treatment. Appl. Surf. Sci. 2010, 256, 6941-6944. [CrossRef]

14. Sianipar, M.; Kim, S.H.; Iskandar, F.; Wenten, I.G. Functionalized carbon nanotube (cnt) membrane: Progress and challenges. RSC Adv. 2017, 7, 51175-51198. [CrossRef]

15. Rahman, M.J.; Mieno, T. Safer production of water dispersible carbon nanotubes and nanotube/cotton composite materials. In Carbon Nanotubes-Current Progress of Their Polymer Composites; InTech: Rijeka, Croatia, 2016.

16. Sharma, B.; Sharma, S.; Gupta, S.; Srivastava, A.; Kumar, A. Combined Effect of Surface Treatment and Surfactant on CNT Nanofluids Preparation. In Proceedings of the 3rd World Congress on New Technologies (NewTech'17), Rome, Italy, 3-5 August 2017.

17. Nayak, L.; Rahaman, M.; Giri, R. Surface modification/functionalization of carbon materials by different techniques: An overview. In Carbon-Containing Polymer Composites; Springer: Berlin/Heidelberg, Germany, 2019; pp. 65-98.

18. Naqvi, S.T.R.; Rasheed, T.; Hussain, D.; ul Haq, M.N.; Majeed, S.; Ahmed, N.; Nawaz, R. Modification strategies for improving the solubility/dispersion of carbon nanotubes. J. Mol. Liq. 2020, 297, 111919. [CrossRef]

19. Lee, J.; Kim, M.; Hong, C.K.; Shim, S.E. Measurement of the dispersion stability of pristine and surface-modified multiwalled carbon nanotubes in various nonpolar and polar solvents. Meas. Sci. Technol. 2007, 18, 3707. [CrossRef]

20. Wang, J. Flame retardancy and dispersion of functionalized carbon nanotubes in thiol-ene nanocomposites. Polymers 2021, 13, 3308. [CrossRef]

21. De Menezes, B.; Ferreira, F.; Silva, B.; Simonetti, E.; Bastos, T.; Cividanes, L.; Thim, G. Effects of octadecylamine functionalization of carbon nanotubes on dispersion, polarity, and mechanical properties of cnt/hdpe nanocomposites. J. Mater. Sci. 2018, 53, 14311-14327. [CrossRef]

22. Yin, F.; Hu, P.; Ma, Y.-H.; Luo, Y.; Wang, C.; Zhu, W.; Lu, X. Polar solvents induce sum frequency generation activity for multiwalled carbon nanotubes. Langmuir 2021. 37, 6540-6548 [CrossRef]

23. Shieh, Y.-T.; Liu, G.-L.; Wu, H.-H.; Lee, C.-C. Effects of polarity and pH on the solubility of acid-treated carbon nanotubes in different media. Carbon 2007, 45, 1880-1890. [CrossRef]

24. Azar, N.S.; Pourfath, M. Aggregation kinetics and stability mechanisms of pristine and oxidized nanocarbons in polar solvents. J. Phys. Chem. C 2016, 120, 16804-16814. [CrossRef]

25. Lapuerta, M.; Canoira, L. The suitability of fatty acid methyl esters (fame) as blending agents in jet a-1. In Biofuels for Aviation; Elsevier: Amsterdam, The Netherlands, 2016; pp. 47-84.

26. Alafogianni, P.; Dassios, K.; Farmaki, S.; Antiohos, S.; Matikas, T.; Barkoula, N.-M. On the efficiency of uv-vis spectroscopy in assessing the dispersion quality in sonicated aqueous suspensions of carbon nanotubes. Colloids Surf. A Physicochem. Eng. Asp. 2016, 495, 118-124. [CrossRef]

27. Pircheraghi, G.; Foudazi, R.; Manas-Zloczower, I. Characterization of carbon nanotube dispersion and filler network formation in melted polyol for nanocomposite materials. Powder Technol. 2015, 276, 222-231. [CrossRef]

28. Jung, W.R.; Choi, J.H.; Lee, N.; Shin, K.; Moon, J.-H.; Seo, Y.-S. Reduced damage to carbon nanotubes during ultrasound-assisted dispersion as a result of supercritical-fluid treatment. Carbon 2012, 50, 633-636. [CrossRef]

29. Shi, Y.; Ren, L.; Li, D.; Gao, H.; Yang, B. Optimization conditions for single-walled carbon nanotubes dispersion. J. Surf. Eng. Mater. Adv. Technol. 2013, 3, 6. [CrossRef]

30. Tham, G.X.; Fisher, A.C.; Webster, R.D. Voltammetric studies on surface-modified electrodes with functionalised carbon nanotubes under different dispersion conditions. Electrochim. Acta 2020, 357, 136880. [CrossRef]

31. Kanoun, O.; Müller, C.; Benchirouf, A.; Sanli, A.; Dinh, T.N.; Al-Hamry, A.; Bu, L.; Gerlach, C.; Bouhamed, A. Flexible carbon nanotube films for high performance strain sensors. Sensors 2014, 14, 10042-10071. [CrossRef] [PubMed]

32. Sanli, A.; Müller, C.; Kanoun, O.; Elibol, C.; Wagner, M.F.-X. Piezoresistive characterization of multi-walled carbon nanotube-epoxy based flexible strain sensitive films by impedance spectroscopy. Compos. Sci. Technol. 2016, 122, 18-26. [CrossRef] 